\title{
Shape-memory properties of magnetically active triple-shape nanocomposites based on a grafted polymer network with two crystallizable switching segments
}

\author{
U. Narendra Kumar, K. Kratz, M. Behl, A. Lendlein* \\ Center for Biomaterial Development and Berlin-Brandenburg Center for Regenerative Therapies, Institute of Polymer \\ Research, Helmholtz-Zentrum Geesthacht, Kantstr. 55, 14513 Teltow, Germany
}

Received 20 May 2011; accepted in revised form 19 July 2011

\begin{abstract}
Thermo-sensitive shape-memory polymers (SMP), which are capable of memorizing two or more different shapes, have generated significant research and technological interest. A triple-shape effect (TSE) of SMP can be activated e.g. by increasing the environmental temperature $\left(T_{\text {env }}\right)$, whereby two switching temperatures $\left(T_{\mathrm{sw}}\right)$ have to be exceeded to enable the subsequent shape changes from shape (A) to shape (B) and finally the original shape (C).

In this work, we explored the thermally and magnetically initiated shape-memory properties of triple-shape nanocomposites with various compositions and particle contents using different shape-memory creation procedures (SMCP). The nanocomposites were prepared by the incorporation of magnetite nanoparticles into a multiphase polymer network matrix with grafted polymer network architecture containing crystallizable poly(ethylene glycol) (PEG) side chains and poly( $\varepsilon$ caprolactone) (PCL) crosslinks named CLEGC.

Excellent triple-shape properties were achieved for nanocomposites with high PEG weight fraction when two-step programming procedures were applied. In contrast, single-step programming resulted in dual-shape properties for all investigated materials as here the temporary shape (A) was predominantly fixed by PCL crystallites.
\end{abstract}

Keywords: polymer composites, smart polymers, nanocomposites, shape-memory polymer, magnetically active polymer

\section{Introduction}

Shape-memory polymers (SMP) and composites thereof belong to the class of actively moving polymers, which have the capability of storing one (dualshape) [1-6], two (triple-shape) [7-13] or multiple (multiple-shape) [14] stable temporary shapes and recover their original or other temporary shapes when exposed to an external stimulus.

The field of SMP research has developed rapidly over the last years $[6,15-25]$ and it has become apparent that these functional polymers are motivating novel applications.

Thermo-sensitive SMP contain physical or chemical network-points, which determine their original shape, while each temporary shape is fixed by switching domains associated to a thermal transition temperature $T_{\text {trans, }}$, that can be a glass transition $\left(T_{\mathrm{g}}\right)$ or a melting transition $\left(T_{\mathrm{m}}\right)[16,17]$. The process for programming of a temporary shape is called 'shapememory creation procedure' (SMCP) and can be realized e.g. by deforming the material to an extension of $\varepsilon_{\mathrm{m}}$ at $T>T_{\text {trans }}$ and cooling to $T<T_{\text {trans }}$ while keeping the deformation, which then is fixed temporarily by solidification of the related set of switching domains [26]. The recovery of the original shape is named shape-memory effect (SME), which is typically induced by increasing the environmental temperature $\left(T_{\text {env }}\right)[3,5,27,28]$, where the shape changes

\footnotetext{
${ }^{*}$ Corresponding author, e-mail: andreas.lendlein@hzg.de (c) BME-PT
} 
can be characterized by the switching temperature $T_{\mathrm{sw}}$ [26], that needs to be exceeded. Non contact initiation of SME was realized by irradiation with infrared light [29-31], applying radio-frequency (RF) [32], or an alternating magnetic field [4, 10, 33-36]. The magnetically triggered SME can be characterized by a specific switching magnetic field strength $H_{\text {sw }}$, which needs to be exceeded to induce the shape change [10]. The inductive heating capability of SMP composites is a result of energy absorption by the embedded magnetic particles from the alternating magnetic field, which is transformed into heat. Three different mechanisms of heat generation have to be considered; eddy current losses (which are a minor effect as e.g. magnetite has very low electrical conductivity), hysteresis losses (during reversal of magnetization), and rotational losses (related to rotation of magnetic moments relative to the surrounding described by Neel and Brownian effects) $[37,38]$.

In the current study, we explored, whether the shape-memory properties of triple-shape nanocomposites achieved by thermal and indirectly by magnetical stimulation of SME could be adjusted by variation of the applied programming protocols.

Magnetically-induced triple-shape nanocomposites, with different switching segment ratios and various nanoparticle contents $(2.5,5$ and $10 \mathrm{wt} \%)$ were synthesized from crystallizable poly( $\varepsilon$-caprolactone) diisocyanatoethyl methacrylate (PCLDIMA; $M_{\mathrm{n}}=$ $\left.8300 \mathrm{~g} \cdot \mathrm{mol}^{-1}, T_{\mathrm{m}, \mathrm{PCL}}=55^{\circ} \mathrm{C}\right)$, crystallizable poly(ethylene glycol) monomethyl ether monomethacrylate $\left(\right.$ PEGMA; $M_{\mathrm{n}}=1000 \mathrm{~g} \cdot \mathrm{mol}^{-1}, T_{\mathrm{m}, \mathrm{PEG}}=38^{\circ} \mathrm{C}$ ) and silica coated magnetite nanoparticles (SNP), named CLEGC, $[39,40]$ according to a procedure previously described in ref. [41]. The matrix material is a grafted polymer network structure based on covalently crosslinked PCL chains with grafted PEG side chains as previously reported $[8,42,43]$. Silica coated nanoparticles were chosen showing improved compatibility with the polymer matrix in comparison to uncoated fillers. To minimize changes in the surface to volume ratio $(S / V)$ during shape recovery and thus ensuring precise control of the temperatures achieved for the nanocomposites during application of an alternating magnetic field, bending experiments were chosen for both thermal and indirect magnetical stimulation according to the method reported in ref. [10]. As it was demonstrated that a triple-shape effect could be achieved for multiphase $\mathrm{AB}$ polymer networks programmed by a one-step or two-step SMCP [44], here we want to investigate the influence of different SMCPs on the shapememory properties of polymer network nanocomposites with grafted polymer network architecture.

\section{Experimental section \\ 2.1. Materials}

The telechelic crosslinker poly( $\varepsilon$-caprolactone) diisocyanatoethyl dimethacrylate (PCLDIMA) was synthesized from poly( $\varepsilon$-caprolactone)diol (Solvay chemicals, Warrington, UK) with a number average molecular weight of $M_{\mathrm{n}}=8.300 \mathrm{~g} \cdot \mathrm{mol}^{-1}$ and 2-isocyanatoethyl methacrylate (Sigma-Aldrich, Taufkirchen, Germany) according to the method described in ref. [10]. Poly(ethylene glycol) monomethyl ether monomethacrylate (PEGMA) (Polysciences, Warrington, PA, USA), benzyl peroxide (Sigma-Aldrich, Taufkirchen, Germany) and silica coated magnetite nanoparticles (AdNano MagSilica 50, Degussa, Hanau, Germany), mean aggregate size (photon correlation spectroscopy of an aqueous dispersion) was $90 \mathrm{~nm}$, the mean domain size (X-ray diffraction) was $20-26 \mathrm{~nm}$, and the domain content (X-ray fluorescence analysis) was 50-60 wt $\%$ were used as received.

\subsubsection{Synthesis of polymer network nanocomposites}

The nanocomposite preparation was following a method described in [41]. Here the synthesis is exemplarily described for CLEG040C05 containing $40 \mathrm{wt} \%$ of PCLDIMA relative to the organic components and a filler content of $5 \mathrm{wt} \%$ in the starting reaction mixture. A mixture of $2.8 \mathrm{~g}$ of PCLIDMA and $4.2 \mathrm{~g}$ of PEGMA were heated to $80^{\circ} \mathrm{C}$, and then $0.37 \mathrm{~g}$ silica-coated nanoparticles were incorporated to the prepolymer melt by mechanical stirring. This mixture was kept at $80^{\circ} \mathrm{C}$ under vacuum for 30 min to remove volatile components, which could generate bubbles during polymerization. The polymerization was started thermally by decomposition of $10.6 \mathrm{mg}$ benzyl peroxide, which was added under stirring. The reaction mixture is placed between two glass plates separated with a $1 \mathrm{~mm}$ thick PTFE spacer and kept at $80^{\circ} \mathrm{C}$ for 24 hours. 


\subsection{Methods}

\subsubsection{Swelling experiments}

For evaluation of the crosslinking reaction, polymer network nanocomposites were extracted with chloroform and water. The gel content $G$ was calculated according to Equation (1), as quotient of the mass of the extracted and dried films $\left(m_{\mathrm{d}}\right)$ to the mass of the original sample $\left(m_{\mathrm{c}}\right)$ :

$G=\frac{m_{\mathrm{d}}}{m_{\mathrm{c}}} \cdot 100 \%$

Additionally, the volumetric degree of swelling $(Q)$, which is a measure for the crosslinking density of a polymer network, was calculated using Equation (2), determined from $m_{\mathrm{c}}$ and $m_{\mathrm{s}}$ and the specific densities of the solvent $\left(\rho_{\mathrm{s}}\right)$ and the network mate$\operatorname{rial}\left(\rho_{\mathrm{m}}\right)$ :

$Q=\left[1+\frac{\rho_{\mathrm{m}}}{\rho_{\mathrm{s}}} \cdot\left(\frac{m_{\mathrm{s}}}{m_{\mathrm{c}}}-1\right)\right] \cdot 100 \%$

\subsubsection{Thermogravimetric analysis (TGA)}

TGA experiments for determination of the incorporated amount of magnetite particles were performed on Netzsch TGA 204 Phoenix (Selb, Germany). All experiments were conducted with a constant heating rate of $20 \mathrm{~K} \cdot \mathrm{min}^{-1}$. The network samples were heated from 25 to $500^{\circ} \mathrm{C}$ under $\mathrm{N}_{2}$ atmosphere and then from 500 to $900^{\circ} \mathrm{C}$ under $\mathrm{O}_{2}$ atmosphere. Temperature was kept constant for $2 \mathrm{~min}$ at $500^{\circ} \mathrm{C}$.

\subsubsection{Differential scanning calorimetry (DSC)}

DSC experiments were performed on a Netzsch DSC 204 Phoenix (Netzsch, Selb, Germany). All experiments were conducted in the temperature range from -100 to $100^{\circ} \mathrm{C}$ with a constant heating and cooling rate of $10 \mathrm{~K} \cdot \mathrm{min}^{-1}$ and with a waiting period of $2 \mathrm{~min}$ at the maximum and minimum temperature. Melting and glass transition temperatures were determined from the second heating run. The overall heat of fusion $\Delta H_{\mathrm{m}}$ as well as the partial heat of fusion $\Delta H_{\mathrm{m}, \mathrm{PXX}}$ representing the crystalline PCL and PEG phases respectively, which was calculated from $\Delta H_{\mathrm{m}}$ and the weight fraction of PCL and PEG phase in the polymer network matrix, were averaged from DSC runs of three different samples.

\subsubsection{Dynamic mechanical analysis at varied temperature (DMTA)}

DMTA analysis was performed on a Gabo Eplexor $25 \mathrm{~N}$ (Gabo, Ahlden, Germany) using standard test specimen (ISO 527-2/1BB) punched from the polymer network films. All experiments were performed in temperature sweep mode with a constant heating rate of $2 \mathrm{~K} \cdot \mathrm{min}^{-1}$. The oscillation frequency was $10 \mathrm{~Hz}$. The network samples were investigated in an temperature interval from -100 to $100^{\circ} \mathrm{C}$.

\subsubsection{Tensile tests}

Tensile tests at different temperatures $\left(0,40,70^{\circ} \mathrm{C}\right.$ and ambient temperature) were performed on Zwick Z 1.0 tensile testers (Zwick, Ulm, Germany) equipped with a thermo chamber and temperature controller (Eurotherm Regler, Limburg, Germany) using standard test specimen (ISO 527-2/1BB). In each experiment the strain rate was $5 \mathrm{~mm} \cdot \mathrm{min}^{-1}$.

\subsubsection{Shape-memory creation procedures}

Bending of the nanocomposite samples (size: $30 \times 2 \times 1 \mathrm{~mm}^{3}$ ) was performed using a custom built device. For controlled heating of the samples to $T_{\text {high }}=70^{\circ} \mathrm{C}$ and $T_{\text {mid }}=40^{\circ} \mathrm{C}$ a thermal oven VD 23 Vacuum Oven, type 21023200002000 (WTB Binder $\mathrm{GmbH}$, Tuttlingen, Germany) was utilized, whereas for cooling to $T_{\text {low }}=0^{\circ} \mathrm{C}$ the freezer of a refrigerator comfort KT1430 (Liebherr, Ochsenhausen, Germany) was applied. A one-step programming (SMCP-1s) and two different two-step shape-memory creation procedures (SMCP-2s-I, SMCP-2s-II) were applied, which are schematically illustrated in Figure 1a. The molecular mechanism of the temporary shape fixation is schematically shown in Figure $1 b$.

\section{SMCP-1S}

The original straight samples (shape (C)) were heated to $T_{\text {high }}=70^{\circ} \mathrm{C}$ and deformed by bending to an angle of $180^{\circ}$, which was fixed afterwards by cooling to $T_{\text {low }}=0^{\circ} \mathrm{C}$ while the bending strain was kept constant. After a waiting period of 10 minutes, the external stain was removed and shape (A) was achieved. 


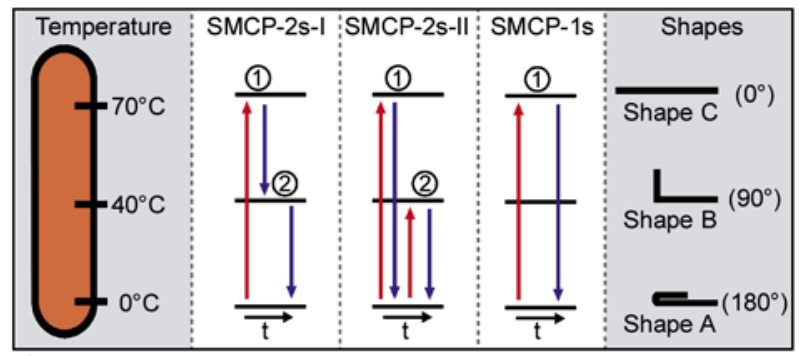

a)

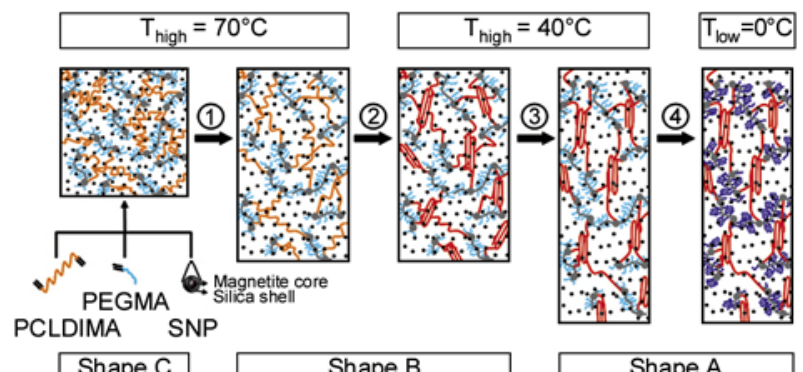

b)

Shape A

Figure 1. (a) Schematic representations of the different shape-memory creation procedures applied for bending of the nanocomposites. Two-step programming methods: SMCP-2s-I, SMCP-2s-II as well as single-step programming procedure SMCP-1s. (b) Molecular mechanism for graft polymer network composites during shape-memory creation procedure where the color indicating the different phases of the polymer segments. Orange: amorphous PCL chain segments, Light blue: amorphous PEG chain segments, Red: crystalline PCL chain segments, Dark blue: crystalline PEG chain segments, grey: amorphous poly(methacrylate) chain segments.

$S M C P-2 s-I$

In step 1 the original sample was heated to $T_{\text {high }}=$ $70^{\circ} \mathrm{C}$ and bent to an angle of $90^{\circ}$, which was fixed by cooling to $T_{\text {mid }}=40^{\circ} \mathrm{C}$ while keeping the bending strain. After a waiting period of 3 hours, the external strain was removed, and the shape (B) was obtained. Subsequent bending to $180^{\circ}$ at $T_{\text {mid }}$, followed by cooling under bending strain to $T_{\text {low }}=0^{\circ} \mathrm{C}$ and equilibration at $T_{\text {low }}$ resulted in shape (A) after removal of the strain.

\section{$S M C P-2 s-I I$}

First the sample was heated to $T_{\text {high }}=70^{\circ} \mathrm{C}$ and deformed by bending to an angle of $90^{\circ}$, which was fixed by cooling to $T_{\text {low }}=0^{\circ} \mathrm{C}$ while the bending strain was kept constant. After equilibration for 1 minute, the external strain was removed and step 1 was completed, while shape (B) was achieved. In

step 2 the sample was heated to $T_{\text {mid }}$ and bent to $180^{\circ}$, which was fixed by cooling to $T_{\text {low }}=0^{\circ} \mathrm{C}$ under keeping the bending strain. After equilibration at $T_{\text {low }}$ the strain was removed to obtain shape (A).

\subsubsection{Indirect magnetic heating experiments}

Inductive heating of the nanocomposites samples was realized by positioning original and programmed nanocomposite samples in an alternating magnetic field at a frequency of $f=258 \mathrm{kHz}$. The experimental set-up consisted of a high-frequency generator (TIG 5/300; Huettinger Electronic, Freiburg, Germany), a water-cooled coil with 6 loops with a diameter of $4 \mathrm{~cm}$, for application of magnetic field and an IR pyrometer (Metis MY84, Sensortherm; Frankfurt, Germany) for online non-contact measurement of the sample's surface temperature $\left(T_{\max }\right)$. By adjusting the generator power output the magnetic field strength $H$ in the centre of the coil could be varied. The magnetically induced shape change was recorded with a digital compact camera (Canon PowerShot A460) and the change in recovery angle was determined with the help of the single photographs taken every $10 \mathrm{~s}$.

Two different kinds of indirect magnetic heating experiments were conducted. In a first set of experiments the magnetic field strength was increased step-wise $\left(\approx 1 \mathrm{kA} \cdot \mathrm{m}^{-1}\right)$ from $H_{0}=0 \mathrm{kA} \cdot \mathrm{m}^{-1}$ to $H=$ $29.4 \mathrm{kA} \cdot \mathrm{m}^{-1}$ and from the obtained recovery curves $H_{\text {sw }}$ was determined. In a second recovery experiment $H$ was subsequently switched from $H_{0}$ to $H_{\text {mid }}=22.2 \mathrm{kA} \cdot \mathrm{m}^{-1}$ and after a waiting period of 3 minutes $H$ was again increased from $H_{\text {mid }}=$ $22.2 \mathrm{kA} \cdot \mathrm{m}^{-1}$ to $H_{\text {high }}=29.4 \mathrm{kA} \cdot \mathrm{m}^{-1}$.

\subsubsection{Environmental heating experiments}

Heating of nanocomposites was performed by utilization of a thermochamber equipped with a temperature controller (2216E for the Z005, Eurotherm Regler, Limburg, Germany). Heating in the thermochamber was realized by increasing $T_{\text {env }}$ from 25 to $70^{\circ} \mathrm{C}$ with a heating rate of $3 \mathrm{~K} \cdot \mathrm{min}^{-1}$, while $T_{\text {env }}$ was measured by a $\mathrm{Cu}-\mathrm{CuNi}$ thermocouple, which was placed close to the sample. The shape changes were recorded with a video camera (Canon Powershot A 460) and the recovery angle was determined with the help of single photographs taken at different $T_{\text {env. }}$. 


\section{Results and discussion}

\subsection{Composition and morphology of the composites}

CLEGC triple-shape nanocomposites with 30 to $70 \mathrm{wt} \%$ PCLDIMA in the starting material mixture of organic compounds and a nanoparticle content from $0,2.5,5$ or $10 \mathrm{wt} \%$ SNP were synthesized by thermally initiated radical polymerization. The nomenclature of the different nanocomposites as well as the composition related results are given in Table 1.

The gel content $G$ determined in swelling experiments by extraction with chloroform was used to quantify the yield of the crosslinking reaction. Constant high values for $G\left(\mathrm{CHCl}_{3}\right)$ in the range around 92 to $96 \%$ were obtained for all materials independent from the network composition indicating an almost complete reaction. The obtained degree of swelling values $Q\left(\mathrm{CH}_{3} \mathrm{Cl}\right)$ and $Q\left(\mathrm{H}_{2} \mathrm{O}\right)$ decreased with increasing crosslinker content from 1020 to $890 \%$ and from 270 to $130 \%$, respectively. The composition of the polymer network was confirmed by water extraction method according Equation (3), where $\omega_{\mathrm{PCL} \text {,initial }}$ is the initial PCL-wt $\%$ in the starting composition and $\omega_{\mathrm{PCL}}$ is the incorporated PCLwt $\%, G\left(\mathrm{H}_{2} \mathrm{O}\right)$ and $G\left(\mathrm{CHCl}_{3}\right)$ are the gel content values determined in water and chloroform:

$\omega_{\mathrm{PLC}}=\left(\frac{\omega_{\mathrm{PLC}, \text { initial }}-\left[G\left(\mathrm{H}_{2} \mathrm{O}\right)-G\left(\mathrm{CHCl}_{3}\right)\right]}{G\left(\mathrm{CHCl}_{3}\right)}\right) \cdot 100 \%$

The amount of incorporated SNP for the nanocomposites determined by thermo gravimetric analysis was found to be close to the initial incorporated amount. The distribution of the nanoparticles within the polymer matrices was investigated by means of SEM. The SEM micrographs obtained from cryomicrotomed cross sections of the nanocomposites confirmed a similar filler distribution for samples with $5 \mathrm{wt} \% \mathrm{SNP}$, independent from the composition of the polymer matrix.

\subsection{Thermal and mechanical properties}

The thermal properties of the networks were investigated by DSC and DMTA. The DSC thermograms of the CLEGC samples are shown in Figure 2. All CLEGC exhibited two distinct $T_{\mathrm{m}}$, whereby the $T_{\mathrm{m}}$

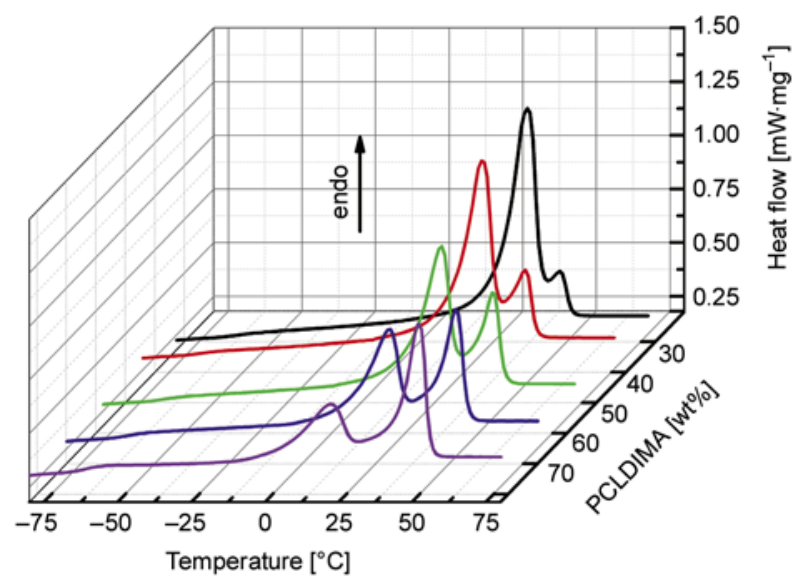

Figure 2. DSC thermograms for nanocomposites with different switching segment ratios and $5 \mathrm{wt} \%$ SNP content taken from the second heating run with a heating rate of $10 \mathrm{~K} \cdot \mathrm{min}^{-1}$. $\mathrm{CLEG}(030) \mathrm{C} 05$ (black line); CLEG(040)C05 (red line); CLEG(050)C05 (green line); CLEG(060)C05 (blue line); CLEG(070)C05 (pink line).

Table 1. Gel content $G$, swelling degree $Q$, SNP content and PCL content of CLEG nanocomposites and pure polymer networks

\begin{tabular}{|c|c|c|c|c|c|c|}
\hline Sample ID ${ }^{[a]}$ & $\begin{array}{c}\mathrm{G}\left(\mathrm{CHCl}_{3}\right)^{[\mathrm{b}]} \\
{[\%]}\end{array}$ & $\begin{array}{c}\mathrm{Q}\left(\mathrm{CHCl}_{3}\right)^{[\mathrm{b}]} \\
{[\%]}\end{array}$ & $\begin{array}{c}\mathrm{G}\left(\mathrm{H}_{2} \mathrm{O}\right)^{[\mathrm{c}]} \\
{[\%]}\end{array}$ & $\begin{array}{c}\mathrm{Q}\left(\mathrm{H}_{2} \mathrm{O}\right)^{[\mathrm{c}]} \\
{[\%]}\end{array}$ & $\begin{array}{c}\text { SNP content }{ }^{[d]} \\
{[w t \%]}\end{array}$ & $\begin{array}{l}\omega_{\mathrm{PCL}}{ }^{[\mathrm{e}]} \\
{[\mathbf{w t} \%]}\end{array}$ \\
\hline CLEG(030)C05 & $94.1 \pm 0.7$ & $1018 \pm 4$ & $97.9 \pm 0.3$ & $266 \pm 0$ & $5.2 \pm 1.0$ & $28 \pm 1$ \\
\hline CLEG(040)C05 & $94.6 \pm 0.3$ & $1007 \pm 5$ & $97.6 \pm 1.0$ & $211 \pm 1$ & $5.2 \pm 0.4$ & $39 \pm 1$ \\
\hline CLEG(050)C05 & $94.2 \pm 0.3$ & $991 \pm 8$ & $98.2 \pm 0.6$ & $173 \pm 0$ & $5.1 \pm 0.4$ & $49 \pm 1$ \\
\hline CLEG(060)C05 & $92.0 \pm 0.4$ & $998 \pm 8$ & $97.4 \pm 0.5$ & $148 \pm 2$ & $5.1 \pm 0.3$ & $60 \pm 1$ \\
\hline CLEG(070)C05 & $92.5 \pm 0.1$ & $954 \pm 2$ & $99.0 \pm 1.2$ & $131 \pm 2$ & $5.0 \pm 0.3$ & $69 \pm 1$ \\
\hline CLEG(030)C00 & $93.5 \pm 1.2$ & $974 \pm 18$ & $96.6 \pm 0.2$ & $272 \pm 3$ & - & $29 \pm 1$ \\
\hline CLEG(040)C00 & $94.4 \pm 0.2$ & $947 \pm 3$ & $97.6 \pm 0.4$ & $213 \pm 1$ & - & $38 \pm 1$ \\
\hline CLEG(050)C00 & $93.9 \pm 0.0$ & $938 \pm 4$ & $98.0 \pm 0.7$ & $174 \pm 2$ & - & $49 \pm 1$ \\
\hline CLEG(060)C00 & $93.2 \pm 0.3$ & $913 \pm 14$ & $98.4 \pm 0.8$ & $147 \pm 1$ & - & $59 \pm 1$ \\
\hline CLEG(070)C00 & $93.0 \pm 0.6$ & $888 \pm 7$ & $99.3 \pm 0.7$ & $128 \pm 1$ & - & $69 \pm 1$ \\
\hline
\end{tabular}

${ }^{[a]}$ Sample ID: the three-digit number in brackets gives the weight content of PCLDIMA in the starting material mixture of the organic compounds in $\mathrm{wt} \%$ and the last two digits represent the $\mathrm{wt} \%$ of added nanoparticles $(0,2.5,5,10)$.

Gel content $(G)$ and swelling degree $(Q)$ determined by swelling experiment in ${ }^{[\mathrm{b}]} \mathrm{CHCl}_{3},{ }^{[\mathrm{c}]} \mathrm{H}_{2} \mathrm{O}$.

${ }^{[d]}$ Particle content in wt $\%$ determined by TGA.

${ }^{[\mathrm{e}]}$ The weight content of PCL in the polymer network matrix determined by water extraction method. 


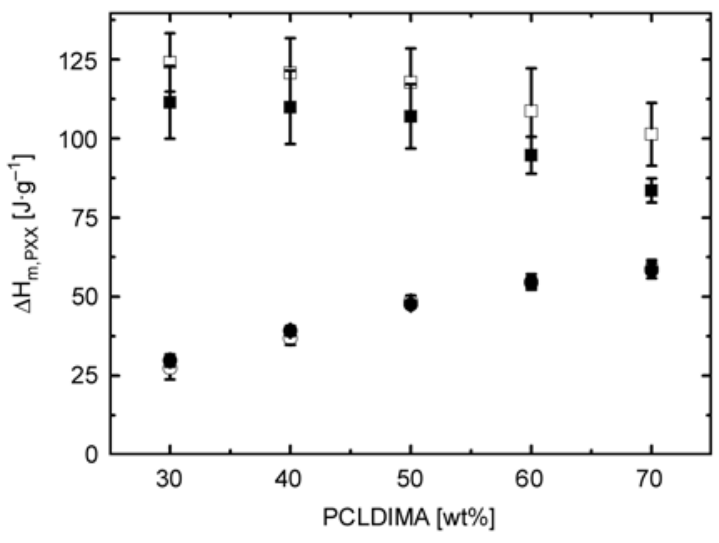

Figure 3. Partial heat of fusion $\left(\Delta H_{\mathrm{m}, \mathrm{PXX}}\right)$ determined by DSC for crystalline PCL and PEG domains of nanocomposites and pure multiphase polymer networks. Nanocomposites: $\Delta H_{\mathrm{m}, \mathrm{PEG}}$ (solid squares); $\Delta H_{\mathrm{m}, \mathrm{PCL}}$ (solid circles); pure polymer networks: $\Delta H_{\mathrm{m}, \mathrm{PEG}}$, (open squares); $\Delta H_{\mathrm{m}, \mathrm{PCL}}$ (open circles).

at lower temperatures $\left(20-40^{\circ} \mathrm{C}\right)$ can be related to the melting of the crystalline PEG phase $\left(T_{\mathrm{m}, \mathrm{PEG}}\right)$ and at higher temperatures $\left(\geq 50^{\circ} \mathrm{C}\right)$ to the melting of PCL crystallites $\left(T_{\mathrm{m}, \mathrm{PCL}}\right)$. The $T_{\mathrm{m}, \mathrm{PCL}}$ remains constant at around $50^{\circ} \mathrm{C}$, whereas $T_{\mathrm{m} \text {,PEG was found }}$ to decrease with increasing switching segment content from 38 to $20^{\circ} \mathrm{C}$ for both nanocomposites and the pure networks. The overall heat of fusion $\Delta H_{\mathrm{m}}$ was found to decrease with increasing PCL content from $\Delta H_{\mathrm{m}}=80 \mathrm{~J} \cdot \mathrm{g}^{-1}$ to $\Delta H_{\mathrm{m}}=64 \mathrm{~J} \cdot \mathrm{g}^{-1}$. While $\Delta H_{\mathrm{m}, \mathrm{PEG}}$ decreased with increasing switching segment content, $\Delta H_{\mathrm{m}, \mathrm{PCL}}$ was found to increase (Figure 3).

The storage modulus $\left(E^{\prime}\right)$ vs. temperature curves obtained from DMTA analysis, are shown in Fig-

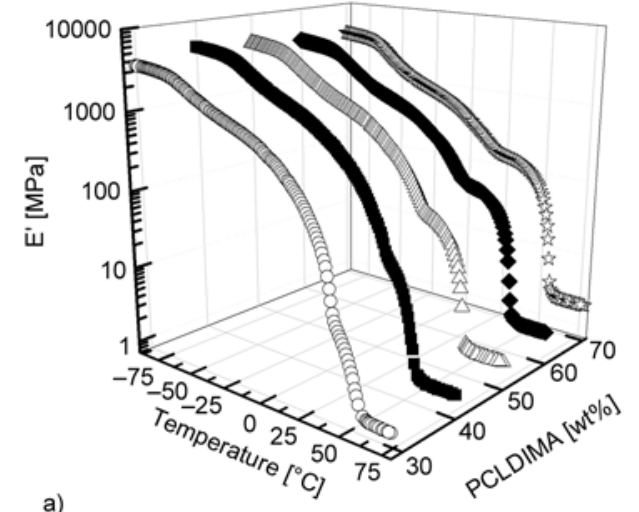

ure 4. The observed glass transition obtained as maximum of the $\tan \delta$ versus temperature curve can be attributed to the amorphous PCL chains and was found in the range from -52 to $-58^{\circ} \mathrm{C}$ for all composites. Both, pure polymer networks as well as nanocomposites, show a systematical decrease of the storage modulus $E^{\prime}$ with increasing temperature (Figure 4a). At temperatures above $-50^{\circ} \mathrm{C}$ the values for $E^{\prime}$ decrease gradually to a level that is strongly dependent on the switching segment content, starting around $25^{\circ} \mathrm{C}$. At $40^{\circ} \mathrm{C}$ above $T_{\mathrm{m}, \mathrm{PEG}}$ the storage modulus of the samples start to decrease sharply until the melting of the PCL crystallites is completed at around $60^{\circ} \mathrm{C}$. Figure $4 \mathrm{~b}$ shows that an incorporation of SNP of 2.5 to $10 \mathrm{wt} \%$ does not significantly alter the thermomechanical properties, whereby $E^{\prime}$ for composites with 5 and $10 \mathrm{wt} \%$ SNP was slightly higher.

Mechanical testing was performed by uniaxial tensile testing at four different temperatures (ambient temperature, $T_{\text {high }}=70^{\circ} \mathrm{C} ; T_{\text {mid }}=40^{\circ} \mathrm{C}$ and $T_{\text {low }}=$ $0^{\circ} \mathrm{C}$ ) and the obtained data are summarized in Figure 5 and Table 2. At $0^{\circ} \mathrm{C}$, where PCL and PEG segments form crystalline as well as amorphous domains, the values of the Young's modulus decreased systematically with increasing switching segment content. This is related to the strong contribution of the crystalline PEG side chains to the overall mechanical properties below the onset of $T_{\mathrm{m}, \mathrm{PEG}}$ at $0^{\circ} \mathrm{C}$ (see Figure 2) which is in good agree-

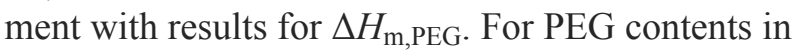
the range of $50-70 \mathrm{wt} \%$ the crystalline PEG domains dominate the overall mechanical proper-

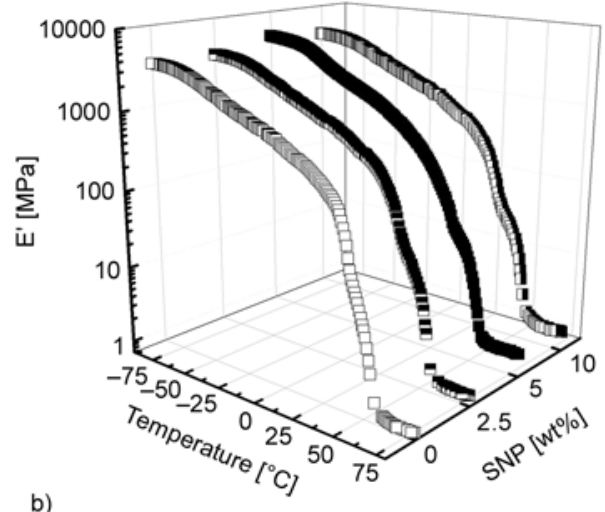

Figure 4. Storage modulus $\left(E^{\prime}\right)$ versus temperature curves obtained for nanocomposites with different switching segment ratios by DMTA measurements. (a) nanocomposites differing in PCL content CLEG(30)C05 (open circles), CLEG(40)C05 (filled squares), CLEG(50)C05 (open triangles), CLEG(60)C05 (filled diamonds), CLEG(70)C05 (open stars), (b) nanocomposites prepared with $40 \mathrm{wt} \%$ PCLDIMA in the starting material mixture with different SNP content CLEG(40)C00 (open squares), CLEG(40)C02 (horizontally half-filled squares), CLEG(40)C05 (solid squares) and CLEG(40)C10 (vertically half-filled squares). 
Table 2. Mechanical properties of pure CLEG polymer networks with various compositions at different temperatures $\left(T_{\text {high }}=70^{\circ} \mathrm{C}, T_{\text {mid }}=40^{\circ} \mathrm{C}\right.$ and $\left.T_{\text {low }}=0^{\circ} \mathrm{C}\right)$.

\begin{tabular}{|c|c|c|c|c|c|c|}
\hline \multirow{2}{*}{ Sample ID ${ }^{[a]}$} & \multicolumn{2}{|c|}{$T_{\text {high }}=7^{\circ} \mathrm{C}$} & \multicolumn{2}{|c|}{$T_{\text {mid }}=40^{\circ} \mathrm{C}$} & \multicolumn{2}{|c|}{$\mathbf{T}_{\text {low }}=0^{\circ} \mathrm{C}$} \\
\hline & E [MPa] & $\varepsilon_{B}[\%]$ & E [MPa] & $\varepsilon_{B}[\%]$ & E [MPa] & $\varepsilon_{B}[\%]$ \\
\hline CLEG(030)C00 & $0.49 \pm 0.01$ & $100 \pm 30$ & $4.2 \pm 0.2$ & $100 \pm 30$ & $430 \pm 50$ & $7 \pm 4$ \\
\hline CLEG(040)C00 & $0.70 \pm 0.02$ & $100 \pm 30$ & $14.7 \pm 0.6$ & $120 \pm 60$ & $420 \pm 20$ & $50 \pm 30$ \\
\hline CLEG(050)C00 & $0.87 \pm 0.01$ & $100 \pm 30$ & $31.1 \pm 1.5$ & $170 \pm 60$ & $310 \pm 30$ & $120 \pm 90$ \\
\hline CLEG(060)C00 & $1.05 \pm 0.03$ & $150 \pm 10$ & $46.5 \pm 2.1$ & $240 \pm 10$ & $130 \pm 20$ & $200 \pm 60$ \\
\hline CLEG(070)C00 & $1.23 \pm 0.03$ & $160 \pm 20$ & $62.7 \pm 10.4$ & $270 \pm 20$ & $160 \pm 10$ & $240 \pm 90$ \\
\hline
\end{tabular}

${ }^{[a]}$ The three-digit numbers in parentheses given for the sample IDs are the content of PCLDIMA in the starting material mixture of the organic compounds in wt $\%$, whereby $\mathrm{C} 00$ indicates that no nanoparticles were incorporated. Elongation at break $\left(\varepsilon_{\mathrm{B}}\right)$ and Young's Modulus $(E)$ determined by tensile tests at different temperatures, $T_{\text {low }}=0^{\circ} \mathrm{C}, T_{\text {mid }}=40^{\circ} \mathrm{C}$ and $T_{\text {high }}=70^{\circ} \mathrm{C}$.

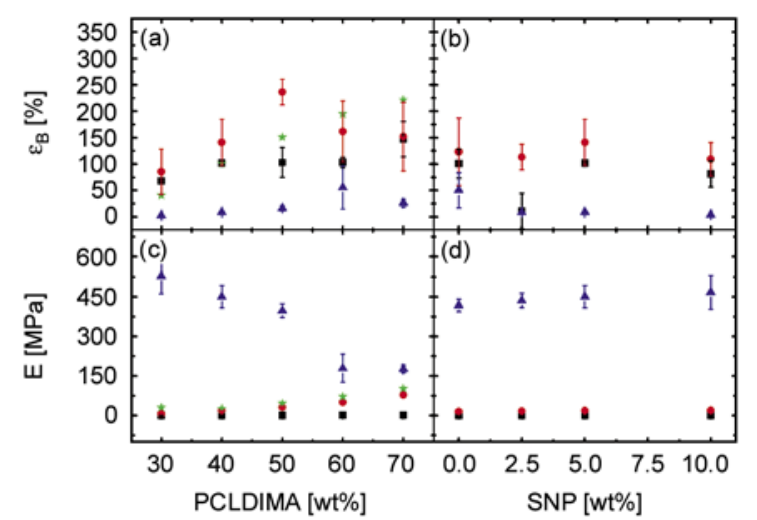

Figure 5. Mechanical properties of nanocomposites CLEG(XX)C05 with $5 \mathrm{wt} \%$ SNP depending on the PCLDIMA content in the starting material mixture and for CLEG(40)C with different SNP content determined by tensile tests at $0^{\circ} \mathrm{C}$ (blue triangles); $40^{\circ} \mathrm{C}$ (red circles); $70^{\circ} \mathrm{C}$ (black squares); ambient temperature (green stars). (a) Elongation at break $\varepsilon_{\mathrm{B}}$ for nanocomposites differing in PCL content; (b) Elongation at break $\varepsilon_{\mathrm{B}}$ for CLEG(40)C with different SNP content; (c) Young's modulus $E$ for nanocomposites with different PCL content; (d) Young's modulus $E$ for CLEG(40)C with different SNP content.

ties, while for the other compositions somehow a balance between PEG and PCL was reached. Therefore, the Young's modulus decreased significantly with decreasing PEG content in the polymer network. The elongation at break $\varepsilon_{\mathrm{B}}$ at $T_{\text {low }}=0^{\circ} \mathrm{C}$ increased with increasing switching segment content, as the PCLDIMA content in the starting mixture is related to the number of covalent crosslinks in the polymer network. At $T_{\text {low }}=0{ }^{\circ} \mathrm{C}$ both composites and pure networks exhibited almost similar mechanical properties. At ambient temperature, where some of the crystalline PEG domains are already molten, an increase in $E$ and $\varepsilon_{\mathrm{B}}$ with increasing switching segment content could be observed, whereby the $E$ values are significantly lower compared to $T_{\text {low }}=0^{\circ} \mathrm{C}$. At $40^{\circ} \mathrm{C}$ the PEG phase was completely amorphous and the PCL phase still remained crystalline. Therefore the PEG phase could not contribute to the mechanical properties. At $70^{\circ} \mathrm{C}$, which is above the melting temperature of both PEG and PCL, all samples are completely amorphous and only the covalent crosslinks introduced by PLCDIMA determine the overall mechanical behavior. While the incorporation of nanoparticles up to a content of $5 \mathrm{wt} \%$ did not significantly alter $\varepsilon_{\mathrm{B}}$ and $E$, for CLEG(040)C10 especially at $0^{\circ} \mathrm{C}$ higher values for the Young's modulus and lower $\varepsilon_{\mathrm{B}}$-values were obtained, which we attribute to the higher filler concentration.

\subsection{Magnetic heating experiments}

Prior to the investigation of shape-memory properties a series of preliminary magnetic field experiments were conducted exemplarily for CLEG(040)C samples with different SNP content, where the maximal achievable temperature $T_{\max }$ was determined increasing $H$ from $H=0$ to $H=29.4 \mathrm{kA} \cdot \mathrm{m}^{-1}$ at constant frequency of $f=258 \mathrm{kHz}$ (details are given in the experimental section). For magnetic nanocomposites the specific absorption rate (SAR) or specific loss power is a key parameter, which is defined as the amount of heat released by a unit weight of the composite material per unit time [38, 40]. It was further reported that SAR is proportional to the observed temperature difference $\Delta T=$ $T_{\max }-T_{\text {env }}$, which can be correlated to the square of the magnetic field strength $\left(H^{2}\right)$ (Equation (4)), where $k$ is a material related constant, which depends on several factors (e.g. size and shape of the magnetic particles, their magnetic properties and the particle content or the heat conductivity of the composite) and the frequency $f$ of the alternating mag- 


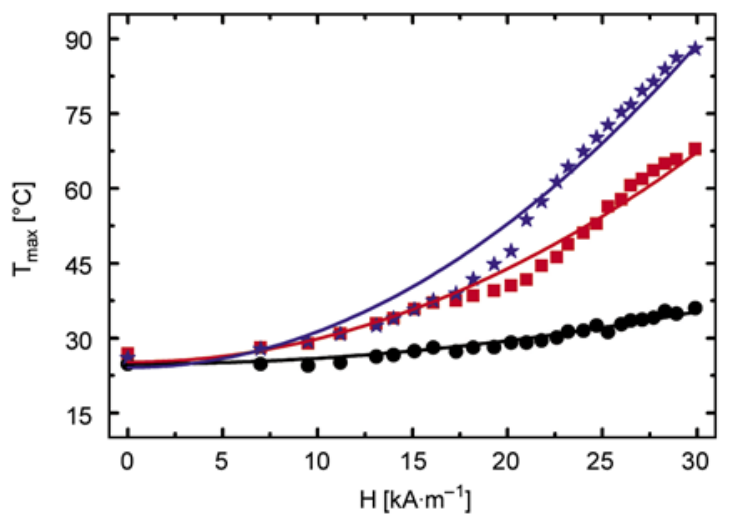

Figure 6. $T_{\max }$ achieved in magnetic heating experiments by continuously increasing $H$ from $H=0 \mathrm{kA} \cdot \mathrm{m}^{-1}$ to $H=29.4 \mathrm{kA} \cdot \mathrm{m}^{-1}$ for $\mathrm{CLEG}(040) \mathrm{C}$ with three different SNP contents; CLEG(040)C02 (black circles), CLEG(040)C05 (red squares) and CLEG(040)C10 (blue stars) and $T_{\text {bulk }}=k \cdot H^{2}+$ $<T_{\text {env }}>$ model analysis (solid lines)

netic field [38]. As in our case a constant frequency of $f=258 \mathrm{kHz}$ was used and the investigated composites differ only in the amount of SNP.

$S A R \cong \Delta T \cong k \cdot H^{2}$

As shown in Figure 6 the obtained $T_{\max }$ achieved by magnetic heating of the composites increased almost significantly with increasing the filler content and increasing $H$. At $H_{\text {high }}=29.4 \mathrm{kA} \cdot \mathrm{m}^{-1}$ only for nanocomposites with 5 and $10 \mathrm{wt} \%$ SNP the required temperatures $T_{\max }>T_{\mathrm{m}, \mathrm{PCL}}$ could be reached. CLEG(040)C05 was selected for performing magnetic recovery experiments, as the thermomechanical properties were almost similar to that of the pure polymer networks. In addition $H$ required for indirect heating to $T_{\mathrm{mid}}=T_{\max }>T_{\mathrm{m}, \mathrm{PEG}}=40^{\circ} \mathrm{C}$ and $T_{\text {high }}=T_{\max }>T_{\mathrm{m}, \mathrm{PCL}}=70^{\circ} \mathrm{C}$ were determined for CLEG(040)C05 to $H_{\text {mid }}=22.2 \mathrm{kA} \cdot \mathrm{m}^{-1}$ and $H_{\text {high }}=29.4 \mathrm{kA} \cdot \mathrm{m}^{-1}$. The inserted model calculation based on Equation (4) showed that $T_{\max }$ correlated with $H^{2}$ as previously reported for other composite systems $[38,40]$. Here it becomes apparent, that for CLEG(040)C02 the obtained data and the theoretical prediction of the model calculation were in good agreement, while CLEG(040)C05 and CLEG(040)C10 showed a significant deviation in the $H$-range of $15 \mathrm{kA} \cdot \mathrm{m}^{-1}$ to $H=22.4 \mathrm{kA} \cdot \mathrm{m}^{-1}$, which might be related to the higher particle loading. The $k$ values obtained by the model analysis were $k=0.012 \mathrm{~K} \cdot \mathrm{m}^{2} \cdot \mathrm{kA}^{-2}$ for CLEG(040)C02, $k=$
$0.047 \mathrm{~K} \cdot \mathrm{m}^{2} \cdot \mathrm{kA}^{-2}$ for $\mathrm{CLEG}(040) \mathrm{C} 05$ and $k=$ $0.072 \mathrm{~K} \cdot \mathrm{m}^{2} \cdot \mathrm{kA}^{-2}$ for CLEG(040)C10.

\subsection{Shape-memory properties}

Bending experiments were performed for studying the shape-memory properties. Here three different thermomechanical shape-memory creation procedures were applied, the two-step creation procedures SMCP-2s-I and SMCP-2s-II as well as the single-step programming SMCP-1s (details are given in Experimental section). In Figure 1a the different SMCPs are presented schematically. In Figure $1 \mathrm{~b}$, the molecular mechanisms of the temporary shape fixation during SMCP-2s-I is shown schematically. The PCL phase is used for the fixation of the temporary shape $\mathrm{B}$, the sample is deformed at $70^{\circ} \mathrm{C}$ (step 1), which leads to an orientation of the amorphous, flexible PCL chain segments. Cooling to $40^{\circ} \mathrm{C}$ results in a crystallization of PCL chain segments (step 2), so that the temporary shape (B) is fixed when the sample is unloaded. At $40^{\circ} \mathrm{C}$, the elasticity of a sample is determined by remaining amorphous PCL chain segments, which can be oriented by applying a deforming stress. This allows further a deformation of the polymer network (step 3), cooling to $0^{\circ} \mathrm{C}$ leads to a crystallization of pendant PEG chain segments (step 4), leading to a fixation of the temporary shape $A$ by the crystalline PEG phase.

Shape recovery experiments were conducted with programmed samples by increasing the environmental temperature $T_{\text {env }}$ and application of two different indirect magnetic heating experiments: stepwise increasing of $H$ and subsequently switching from $H_{0}$ to $H_{\text {mid }}$ and from $H_{\text {mid }}$ to $H_{\text {high }}$ (for details see Experimental section).

For quantification of the shape-memory properties the change in deformation angle $\theta$ was measured during programming and recovery. The shape fixity ratios $R_{\mathrm{f}}(\mathrm{X} \rightarrow \mathrm{Y})$ were determined after completion of SMCP according to Equation (5), while the shape recovery ratios $R_{\mathrm{r}}(\mathrm{Y} \rightarrow \mathrm{X})$ were calculated according to Equation (6). Samples programmed with SMCP-1s were quantified by $R_{\mathrm{f}}(\mathrm{C} \rightarrow \mathrm{A})$ and $R_{\mathrm{r}}(\mathrm{A} \rightarrow \mathrm{C})$, whereas samples programmed by dualstep procedures are characterized by $R_{\mathrm{f}}(\mathrm{C} \rightarrow \mathrm{B})$, $R_{\mathrm{f}}(\mathrm{B} \rightarrow \mathrm{A})$ and the overall fixity ratio $R_{\mathrm{f}}(\mathrm{C} \rightarrow \mathrm{A})$, as well as the recovery ratios $R_{\mathrm{r}}(\mathrm{A} \rightarrow \mathrm{B}), R_{\mathrm{r}}(\mathrm{A} \rightarrow \mathrm{C})$. 
Additionally, the change in bending angle $\Delta \theta_{\text {rec }}$ during recovery with temperature or $H$ was analysed for determination of $T_{\mathrm{sw}}$ and $H_{\mathrm{sw}}$.

$$
\begin{aligned}
& R_{\mathrm{f}}(\mathrm{X} \rightarrow \mathrm{Y})=\frac{\theta_{\mathrm{X}}-\theta_{\mathrm{Y}}}{\theta_{\mathrm{X}}^{0}-\theta_{\mathrm{Y}}} \\
& R_{\mathrm{r}}(\mathrm{Y} \rightarrow \mathrm{X})=\frac{\theta_{\mathrm{Y}}-\theta_{\mathrm{X}}^{\text {rec }}}{\theta_{\mathrm{Y}}-\theta_{\mathrm{X}}}
\end{aligned}
$$

\subsubsection{Recovery by inductive magnetic heating}

All CLEGC nanocomposites exhibited good shapememory properties when activated in alternating magnetic field (see Table 3). An almost complete fixation of shape (B) by crystallization of PCL domains was achieved for all investigated materials independent of the applied SMCP. In contrast the $R_{\mathrm{f}}(\mathrm{B} \rightarrow \mathrm{A})$ obtained during two-step SMCPs was found to decrease with increasing PCL content from $99 \pm 3 \%$ to $73 \pm 3 \%$, because the fixation of shape (A) was mainly supported by the grafted PEG chains. In all magnetic recovery experiments a complete total recovery $R_{\mathrm{r}}(\mathrm{A} \rightarrow \mathrm{C})$ was obtained, while the recovery of shape (B) decreased with increasing PCLDIMA content down to $R_{\mathrm{r}}(\mathrm{A} \rightarrow \mathrm{B})<$ $49 \%$. Excellent triple-shape properties were obtained for the network compositions with 30, 40 and $50 \mathrm{wt} \%$ PCLDIMA content in the starting material mixture. Such composites exhibited $R_{\mathrm{r}}(\mathrm{A} \rightarrow \mathrm{B})$ values above $63 \%$ when SMCP-2s-I was applied and lower values of $R_{\mathrm{r}}(\mathrm{A} \rightarrow \mathrm{B})>55 \%$ for SMCP-2s-II, which can be explained by an additional contribution to fixation of shape (A) caused by cold-drawing of the PCL crystallites during SMCP-2s-I. For nanocomposites programmed with SMCP-1s a complete fixation of the temporary shape (A) and recovery of the original shape (C) was observed. Moreover in Table 4 the shape-memory properties achieved for CLEGC programmed with different SMCPs in magnetic recovery experiments using subsequent switching from $H_{0}$ to $H_{\text {mid }}$ to $H_{\text {high }}$ are summarized.

To determine the switching magnetic field strength $H_{\mathrm{sw}, 1}(\mathrm{~A} \rightarrow \mathrm{B})$ and $H_{\mathrm{sw}, 2}(\mathrm{~B} \rightarrow \mathrm{C})$, inductive magnetic heating was conducted by step-wise increasing of $H$. As apparent from Figure $7 \mathrm{a}-\mathrm{c}$ representing the $\Delta \theta_{\text {rec }}$ versus $H$ curves depending on the PCLDIMA content, the obtained recovery behavior of the nanocomposites was strongly influenced by the compo- sition of the polymer matrix and the applied SMCP. When SMCP-2s-I and SMCP-2s-II was applied, a distinct two-step change in $\Delta \theta_{\text {rec }}$ with increasing $H$ was observed for materials with a PCLDIMA content ranging from 30 to $50 \mathrm{wt} \%$, which is characteristic for triple-shape capability. $H_{\mathrm{sw}, 1}(\mathrm{~A} \rightarrow \mathrm{B})$ increased with decreasing PCLDIMA content, which we attribute to the changes in $T_{\mathrm{m}, \mathrm{PEG}}$ with composition of the polymer matrix as confirmed in DSC measurements. A further difference in $H_{\mathrm{sw}, 1}(\mathrm{~A} \rightarrow \mathrm{B})$ for CLEG(030)C05 and CLEG(040)C05 samples can be related to the difference in the two programming procedures. Here $H_{\mathrm{sw}, 1}(\mathrm{~A} \rightarrow \mathrm{B}) \approx 15 \mathrm{kA} \cdot \mathrm{m}^{-1}$ was determined for samples programmed with SMCP2s-II, while a higher $H_{\mathrm{sw}, 1}(\mathrm{~A} \rightarrow \mathrm{B})>20 \mathrm{kA} \cdot \mathrm{m}^{-1}$ was achieved by SMCP-2s-I. This difference in $H_{\mathrm{sw}, 1}(\mathrm{~A} \rightarrow \mathrm{B})$ can be related to the difference in the two programming procedures. In SMCP-2s-I shape (A) was fixed by PEG crystallites and 'low' melting PCL crystallites resulting in higher values for $H_{\mathrm{sw}, 1}(\mathrm{~A} \rightarrow \mathrm{B})$, whereas during SMCP-2s-II only PEG crystallites are responsible for fixation of shape (A), as previously reported for photocrosslinked CLEG polymer networks [8, 43, 44]. For samples programmed by SMCP-2s-I $H_{\mathrm{sw}, 2}(\mathrm{~B} \rightarrow \mathrm{C}) \approx$ $25 \mathrm{kA} \cdot \mathrm{m}^{-1}$ could be determined, while slightly lower values for $H_{\mathrm{sw}, 2}(\mathrm{~B} \rightarrow \mathrm{C})$ were obtained when SMCP-2s-II was applied. Here, the lower values observed for SMCP-2s-II programmed samples can be related to the contribution of 'low' melting PCL crystallites to the fixation of shape (B) at $T_{\text {low }}=0^{\circ} \mathrm{C}$. When one-step programming SMCP-1s was used for programming, a single transition, which is characteristic for a dual-shape effect, was achieved for all nanocomposites in the $\Delta \theta_{\text {rec }}-H$ curves with $H_{\mathrm{sw}} \approx$ $23 \mathrm{kA} \cdot \mathrm{m}^{-1}$, because the temporary shape is predominantly fixed by PCL crystallites during SMCP-1s, while crystallization of the grafted PEG chains did contribute to the fixation of shape (A) $[43,44]$.

\subsubsection{Recovery by environmental heating}

In thermal recovery experiments, the shape-memory capability of CLEGC composites with different composition was investigated by increasing $T_{\text {env }}$ from 25 to $70^{\circ} \mathrm{C}$ (for details see Experimental section). From the obtained $\Delta \theta_{\text {rec }}$ versus $T_{\text {env }}$ curves $T_{\mathrm{sw}, 1}(\mathrm{~A} \rightarrow \mathrm{B})$ related to the shape change from $\mathrm{A} \rightarrow \mathrm{B}$ and $T_{\mathrm{sw}, 2}(\mathrm{~B} \rightarrow \mathrm{C})$ related to the shape change from $\mathrm{B} \rightarrow \mathrm{C}$ were determined. As apparent from Fig- 


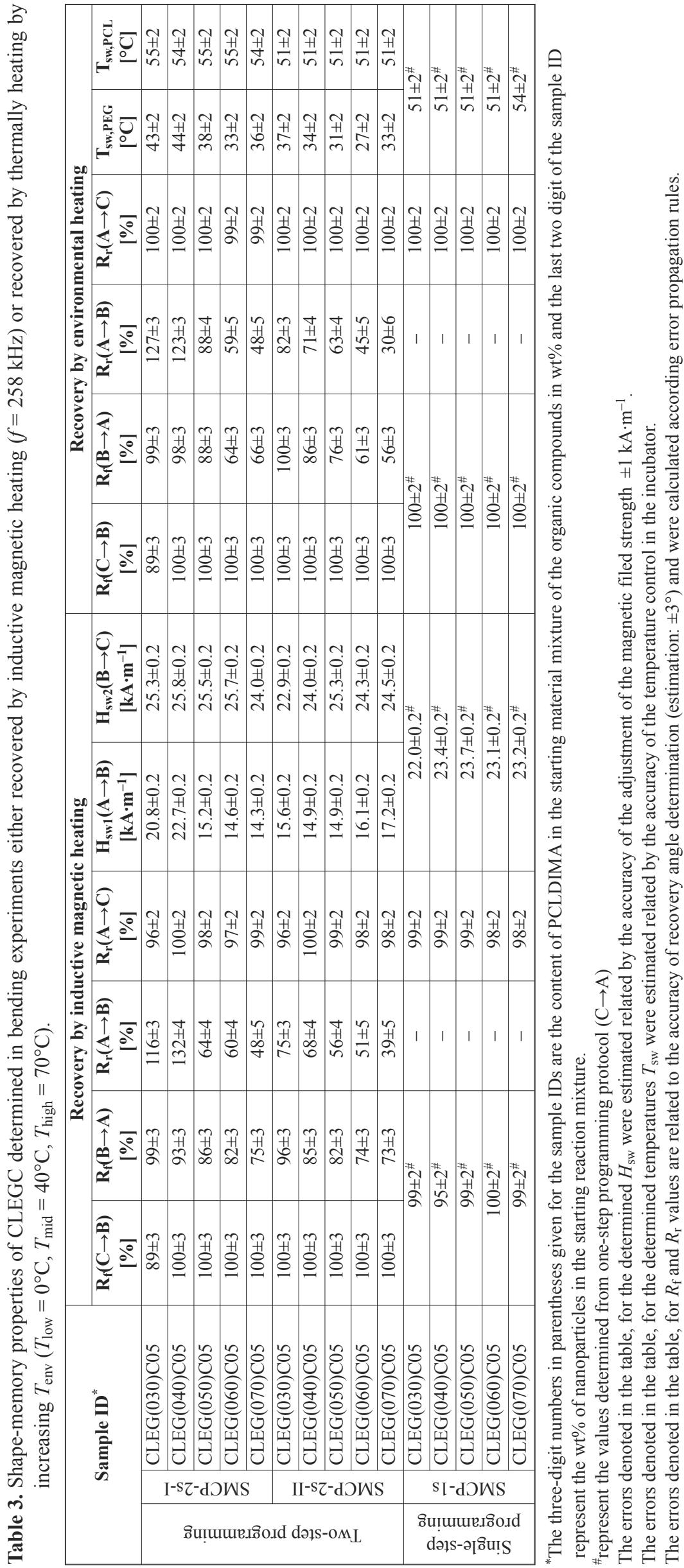




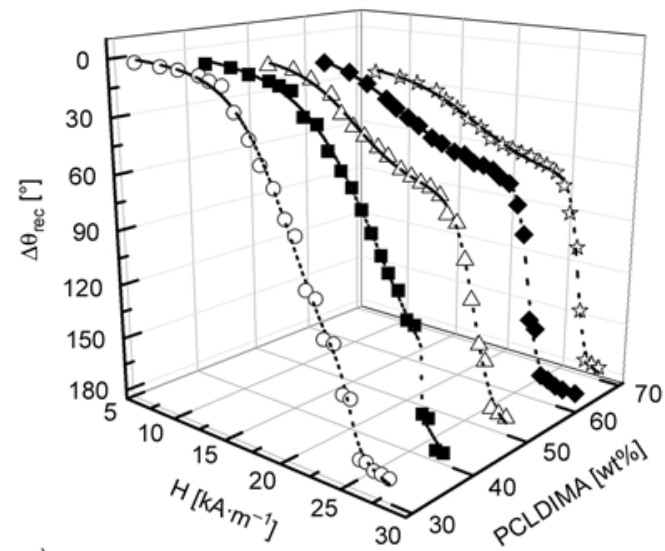

a)
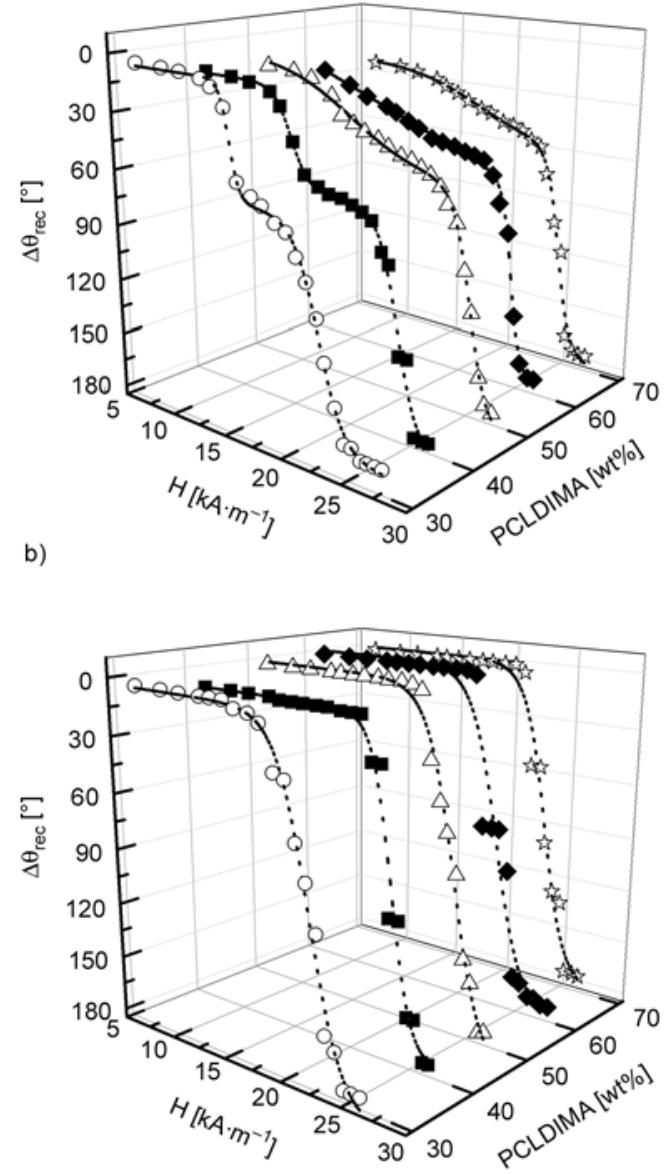

c)
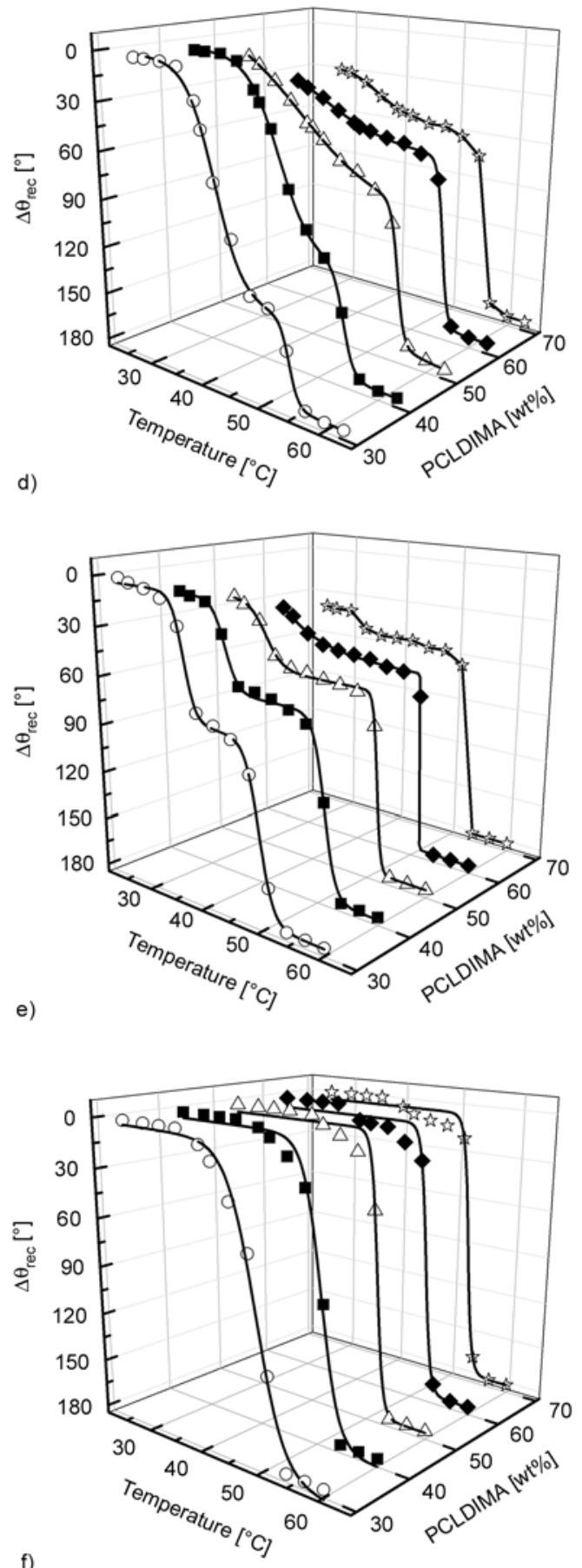

Figure 7. Recovery curves of CLEGC differing in switching segment ratio achieved for different programming procedures either under magnetic activation by step-wise increasing $H$ from $H=0$ to $29.4 \mathrm{kA} \cdot \mathrm{m}^{-1}$ (a), (b), (c) and under thermal stimulation by step-wise increasing $T_{\text {env }}$ from 25 to $70^{\circ} \mathrm{C}$ (d), (e), (f). Samples programmed with programming procedure SMCP-2s-I: (a and d), SMCP-2s-II: (b and e) and SMCP-1s: (c and f). CLEG(030)C05 (open circles); CLEG(040)C05 (filled squares); CLEG(050)C05 (open triangles); CLEG(060)C05 (filled diamonds); CLEG(070)C05 (open stars).

ure $7 \mathrm{~d}-\mathrm{f}$ also the recovery behavior of the nanocomposites, when thermally initiated, was strongly dependent on both the composition of the polymer matrix and the applied SMCP. A pronounced tripleshape behavior characterized by two well separated shape changes with $T_{\text {env }}$ was achieved for all CLEGC composites with PCLDIMA content up to $50 \mathrm{wt} \%$ when programmed with SMCP-2s-I and SMCP-2s-II. The observed increase in $T_{\mathrm{sw}, 1}(\mathrm{~A} \rightarrow \mathrm{B})$ with decreasing PCLDIMA content could be attributed to the 
Table 4. Shape-memory properties of CLEGC determined in inductive magnetic heating experiments where subsequently two different magnetic fields strength $H_{\text {mid }}=22.2 \mathrm{kA} \cdot \mathrm{m}^{-1}$ and $H_{\text {high }}=29.4 \mathrm{kA} \cdot \mathrm{m}^{-1}$ were applied $(f=258 \mathrm{kHz}$, $\left.T_{\text {low }}=0^{\circ} \mathrm{C}, T_{\text {mid }}=40^{\circ} \mathrm{C}, T_{\text {high }}=70^{\circ} \mathrm{C}\right)$.

\begin{tabular}{|c|c|c|c|c|c|c|}
\hline & & Sample ID* & $\begin{array}{c}\mathbf{R}_{\mathrm{f}}(\mathrm{C} \rightarrow \mathrm{B}) \\
{[\%]}\end{array}$ & $\begin{array}{c}\mathrm{R}_{\mathbf{f}}(\mathrm{B} \rightarrow \mathrm{A}) \\
{[\%]}\end{array}$ & $\begin{array}{c}\mathbf{R}_{\mathbf{r}}(\mathbf{A} \rightarrow \mathbf{B}) \\
{[\%]}\end{array}$ & $\begin{array}{c}\mathbf{R}_{\mathrm{r}}(\mathrm{A} \rightarrow \mathrm{C}) \\
{[\%]}\end{array}$ \\
\hline \multirow{10}{*}{ 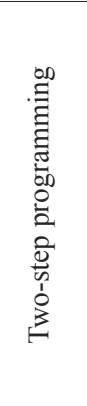 } & \multirow{5}{*}{ 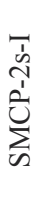 } & CLEG(030)C05 & $89 \pm 3$ & $94 \pm 3$ & $99 \pm 3$ & $100 \pm 2$ \\
\hline & & CLEG(040)C05 & $100 \pm 3$ & $84 \pm 3$ & $72 \pm 4$ & $100 \pm 2$ \\
\hline & & CLEG(050)C05 & $100 \pm 3$ & $80 \pm 3$ & $63 \pm 4$ & $100 \pm 2$ \\
\hline & & CLEG(060)C05 & $100 \pm 3$ & $59 \pm 3$ & $51 \pm 6$ & $100 \pm 2$ \\
\hline & & CLEG(070)C05 & $100 \pm 3$ & $56 \pm 3$ & $46 \pm 6$ & $100 \pm 2$ \\
\hline & \multirow{5}{*}{ 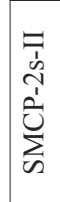 } & CLEG(030)C05 & $94 \pm 3$ & $100 \pm 3$ & $78 \pm 3$ & $100 \pm 2$ \\
\hline & & CLEG(040)C05 & $97 \pm 3$ & $77 \pm 3$ & $69 \pm 4$ & $100 \pm 2$ \\
\hline & & CLEG(050)C05 & $100 \pm 3$ & $76 \pm 3$ & $60 \pm 4$ & $100 \pm 2$ \\
\hline & & CLEG(060)C05 & $100 \pm 3$ & $54 \pm 3$ & $41 \pm 6$ & $100 \pm 2$ \\
\hline & & CLEG(070)C05 & $100 \pm 3$ & $57 \pm 3$ & $63 \pm 6$ & $100 \pm 2$ \\
\hline \multirow{5}{*}{ 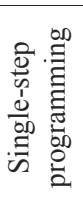 } & \multirow{5}{*}{$\begin{array}{l}\frac{n}{1} \\
\sum_{i=1}^{1}\end{array}$} & CLEG(030)C05 & \multicolumn{2}{|c|}{$100 \pm 2^{\#}$} & - & $100 \pm 2$ \\
\hline & & CLEG(040)C05 & \multicolumn{2}{|c|}{$100 \pm 2^{\#}$} & - & $100 \pm 2$ \\
\hline & & CLEG(050)C05 & \multicolumn{2}{|c|}{$100 \pm 2^{\#}$} & - & $100 \pm 2$ \\
\hline & & CLEG(060)C05 & \multicolumn{2}{|c|}{$100 \pm 2^{\#}$} & - & $100 \pm 2$ \\
\hline & & CLEG(070)C05 & \multicolumn{2}{|c|}{$100 \pm 2^{\#}$} & - & $100 \pm 2$ \\
\hline
\end{tabular}

The errors denoted in the table, for $R_{\mathrm{f}}$ and $R_{\mathrm{r}}$ values are related to the accuracy of recovery angle determination (estimation: $\pm 3^{\circ}$ ) and were calculated according error propagation rules.

*The three-digit numbers in parentheses given for the sample IDs are the content of PCLDIMA in the starting material mixture of the organic compounds in $\mathrm{wt} \%$ and the last two digit of the sample ID represent the $\mathrm{wt} \%$ of nanoparticles in the starting reaction mixture. ${ }$ represent the values determined from one-step programming protocol $(\mathrm{C} \rightarrow \mathrm{A})$

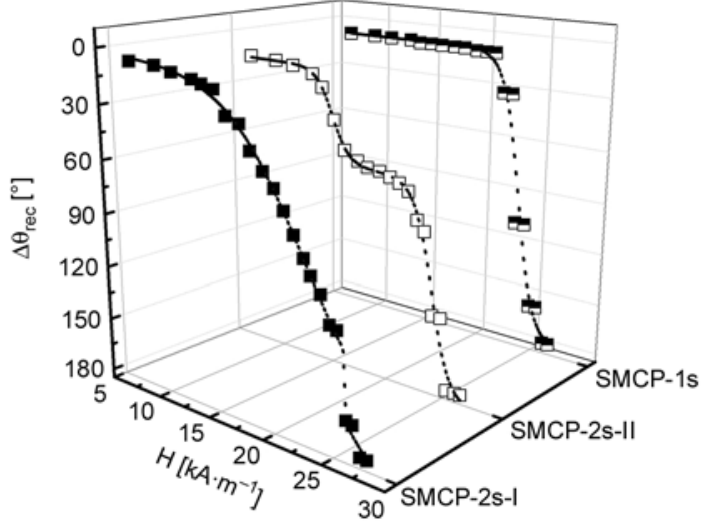

a)

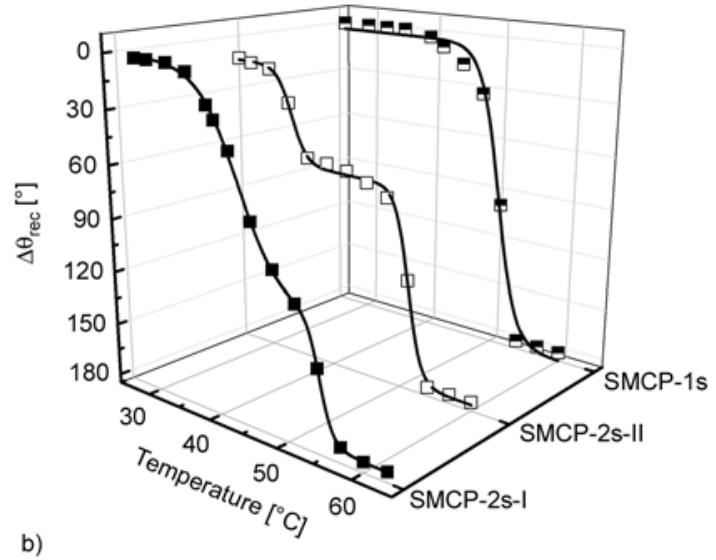

b)

Figure 8. Comparison of thermally- and magnetically-stimulated recovery of CLEG(040)C05 after application of different programming procedures. SMCP-2s-I (filled squares); SMCP-2s-II (open squares); SMCP-1s (horizontally halffilled squares). (a) magnetic activation by step-wise increasing $H$ from 0 to $29.4 \mathrm{kA} \cdot \mathrm{m}^{-1}$ (b) step-wise increasing $T_{\text {env }}$ from $25^{\circ} \mathrm{C}$ to $70^{\circ} \mathrm{C}$.

changes in $T_{\mathrm{m} \text {,PEG }}$ with composition of the polymer matrix as seen in DSC measurements. Whereby slightly higher values of $T_{\mathrm{sw}, 1}(\mathrm{~A} \rightarrow \mathrm{B})$ obtained for SMCP-2s-I could be related to the contribution of 'low' melting PCL crystallites during fixation of shape (A) as aforementioned. In contrast $T_{\mathrm{sw}, 2}(\mathrm{~B} \rightarrow \mathrm{C})$ was found to be independent from the composition of the polymer matrix, while application of SMCP$2 \mathrm{~s}-\mathrm{I}$ resulted in slightly higher values of $T_{\mathrm{sw}, 2}(\mathrm{~B} \rightarrow \mathrm{C})=54^{\circ} \mathrm{C}$, because the fixation of shape (B) is not supported by 'low' melting PCL crystallites.
Finally, in Figure 8 the achieved environmental and magnetic recovery curves obtained for CLEG040C05 using different SMCPs are displayed to illustrate the aforementioned impact of the applied programming procedure on $T_{\mathrm{sw}, 1}(\mathrm{~A} \rightarrow \mathrm{B}), T_{\mathrm{sw}, 2}(\mathrm{~B} \rightarrow \mathrm{C})$, $H_{\mathrm{sw}, 1}(\mathrm{~A} \rightarrow \mathrm{B})$ and $H_{\mathrm{sw}, 2}(\mathrm{~B} \rightarrow \mathrm{C})$.

\section{Conclusions}

A series of CLEGC nanocomposites based on grafted polymer networks with various ratios of two crystallizable switching segments (PCL segments 
acting as covalent crosslinker and grafted PEG segments) and different SNP contents from 2.5 to $10 \mathrm{wt} \%$ were synthesized. High values for gel content $>92 \%$ indicated an almost complete conversion of the starting materials. All nanocomposites exhibited two well separated thermal transitions, $T_{\mathrm{m}, \mathrm{PCL}}=51{ }^{\circ} \mathrm{C}$ attributed to the crystalline PCL domains and $T_{\mathrm{m}, \mathrm{PEG}}$ ranging from 38 to $20^{\circ} \mathrm{C}$ related to crystalline PEG domains, which decreased with increasing in PCL content. The incorporation of SNP up to $5 \mathrm{wt} \%$ did not significantly alter the thermomechanical properties of the grafted polymer network matrix.

The shape-memory properties of the nanocomposites were quantified by bending experiments using three different programming procedures, while activation of the thermally-induced shape effect was realized by indirect magnetic or environmental heating. The results achieved in the different heating experiments were in good accordance. Application of two-step programming procedures SMCP-2s-I and SMCP-2s-II resulted in a distinct triple-shape effect, whereby for nanocomposites with a PCLDIMA weight fraction of 30 and $40 \mathrm{wt} \%$ in the starting reaction mixture excellent triple-shape properties were obtained. In contrast, a pronounced dual-shape effect with an almost complete fixation and recovery were achieved when one-step programming was utilized, because here the temporary shape (A) in this case was predominantly fixed by PCL crystallites, while crystallization of the grafted PEG chains could not contribute to the fixation of shape (A). As for grafted polymer networks with two crystallizable switching segments the application of single-step programming did not lead to triple-shape capability. In a next step AB polymer networks with two crystallizable switching segments should be explored.

\section{References}

[1] Gall K., Dunn M. L., Liu Y., Finch D., Lake M., Munshi N. A.: Shape memory polymer nanocomposites. Acta Materialia, 50, 5115-5126 (2002). DOI: 10.1016/S1359-6454(02)00368-3

[2] Kim B. K., Lee J. S., Lee Y. M., Shin J. H., Park S. H.: Shape memory behavior of amorphous polyurethanes. Journal of Macromolecular Science Part B: Physics, 40, 1179-1191 (2001). DOI: $10.1081 / \mathrm{MB}-100107809$
[3] Lendlein A., Langer R.: Biodegradable, elastic shapememory polymers for potential biomedical applications. Science, 296, 1673-1676 (2002).

DOI: $10.1126 /$ science.1066102

[4] Mohr R., Kratz K., Weigel T., Lucka-Gabor M., Moneke M., Lendlein A.: Initiation of shape-memory effect by inductive heating of magnetic nanoparticles in thermoplastic polymers. Proceedings of the National Academy of Sciences of the United States of America, 103, 3540-3545 (2006).

DOI: $10.1073 /$ pnas.0600079103

[5] Tobushi H., Hayashi S., Ikai A., Hara H.: Thermomechanical properties of shape memory polymers of polyurethane series and their applications. Journal De Physique IV, 6, 377-384 (1996).

DOI: $10.1051 / j p 4: 1996136$

[6] Vaia R., Baur J.: Adaptive composites. Science, 319, 420-421 (2008).

DOI: $10.1126 /$ science. 1152931

[7] Behl M., Lendlein A.: Triple-shape polymers. Journal of Materials Chemistry, 20, 3335-3345 (2010).

DOI: 10.1039/B922992b

[8] Bellin I., Kelch S., Langer R., Lendlein A.: Polymeric triple-shape materials. Proceedings of the National Academy of Sciences of the United States of America, 103, 18043-18047 (2006).

DOI: $10.1073 /$ pnas.0608586103

[9] Luo X., Mather P. T.: Triple-shape polymeric composites (TSPCs). Advanced Functional Materials, 20, 26492656 (2010).

DOI: $10.1002 / \mathrm{adfm} .201000052$

[10] Narendra Kumar U., Kratz K., Wagermaier W., Behl M., Lendlein A.: Non-contact actuation of triple-shape effect in multiphase polymer network nanocomposites in alternating magnetic field. Journal of Materials Chemistry, 20, 3404-3415 (2010).

DOI: $10.1039 / \mathrm{b} 923000 \mathrm{a}$

[11] Pretsch T.: Durability of a polymer with triple-shape properties. Polymer Degradation and Stability, 95, 2515-2524 (2010).

DOI: 10.1016/j.polymdegradstab.2010.07.037

[12] Xie T., Xiao X., Cheng Y-T.: Revealing triple-shape memory effect by polymer bilayers. Macromolecular Rapid Communications, 30, 1823-1827 (2009).

DOI: $10.1002 /$ marc. 200900409

[13] Zotzmann J., Behl M., Hofmann D., Lendlein A.: Reversible triple-shape effect of polymer networks containing polypentadecalactone- and poly( $\varepsilon$-caprolactone)-segments. Advanced Materials, 22, 34243429 (2010). DOI: $10.1002 / \mathrm{adma} .200904202$

[14] Kolesov I. S., Radusch H-J.: Multiple shape-memory behavior and thermal-mechanical properties of peroxide cross-linked blends of linear and short-chain branched polyethylenes. Express Polymer Letters, 2, 461-473 (2008).

DOI: $10.3144 /$ expresspolymlett.2008.56 
[15] Kim B. K.: Shape memory polymers and their future developments. Express Polymer Letters, 2, 614 (2008). DOI: 10.3144/expresspolymlett.2008.73

[16] Behl M., Razzaq M. Y., Lendlein A.: Multifunctional shape-memory polymers. Advanced Materials, 22, 3388-3410 (2010).

DOI: $10.1002 /$ adma.200904447

[17] Behl M., Zotzmann J., Lendlein A.: Shape-memory polymers and shape-changing polymers. Advances in Polymer Science, 226, 1-40 (2010).

DOI: $10.1007 / 12200926$

[18] Hu J., Chen S.: A review of actively moving polymers in textile applications. Journal of Materials Chemistry, 20, 3346-3355 (2010).

DOI: $10.1039 / \mathrm{b} 922872 \mathrm{a}$

[19] Huang W. M., Ding Z., Wang C. C., Wei J., Zhao Y., Purnawali H.: Shape memory materials. Materials Today, 13, 54-61 (2010). DOI: $10.1016 / \mathrm{S} 1369-7021(10) 70128-0$

[20] Lendlein A., Behl M., Hiebl B., Wischke C.: Shapememory polymers as a technology platform for biomedical applications. Expert Review of Medical Devices, 7, 357-379 (2010). DOI: $10.1586 /$ ERD. 10.8

[21] Liu Y., Lv H., Lan X., Leng J., Du S.: Review of electro-active shape-memory polymer composite. Composites Science and Technology, 69, 2064-2068 (2009). DOI: 10.1016/j.compscitech.2008.08.016

[22] Madbouly S. A., Lendlein A.: Shape-memory polymer composites. Shape-Memory Polymers, 226, 41-95 (2010).

DOI: $10.1007 / 12200928$

[23] Mather P. T., Luo X., Rousseau I. A.: Shape memory polymer research. Annual Review of Materials Research, 39, 445-471 (2009).

DOI: 10.1146/annurev-matsci-082908-145419

[24] Ratna D., Karger-Kocsis J.: Recent advances in shape memory polymers and composites: A review. Journal of Materials Science, 43, 254-269 (2008).

DOI: $10.1007 / \mathrm{s} 10853-007-2176-7$

[25] Gunes I. S., Jana S. C.: Shape memory polymers and their nanocomposites: A review of science and technology of new multifunctional materials. Journal of Nanoscience and Nanotechnology, 8, 1616-1637 (2008).

DOI: $10.1166 /$ jnn.2008.038

[26] Wagermaier W., Kratz K., Heuchel M., Lendlein A.: Characterization methods for shape-memory polymers. Advances in Polymer Science, 226, 1-49 (2010). DOI: $10.1007 / 12200925$

[27] Hayashi S.: Properties and applications of polyurethane-series shape memory polymer. in 'International progress in urethanes, Vol. 6' (eds.: Ashida K., Frisch K. C.) CRC Press, Boca Raton, 90-115 (1993).
[28] Huang W. M., Yang B., Zhao Y., Ding Z.: Thermomoisture responsive polyurethane shape-memorypolymer and composites: A review. Journal of Materials Chemistry, 20, 3367-3381 (2010).

DOI: $10.1039 / \mathrm{b} 922943 \mathrm{~d}$

[29] Koerner H., Price G., Pearce N. A., Alexander M., Vaia R. A.: Remotely actuated polymer nanocompositesstress-recovery of carbon-nanotube-filled thermoplastic elastomers. Nature Materials, 3, 115-120 (2004). DOI: $10.1038 /$ nmat1059

[30] Leng J., Zhang D., Liu Y., Yu K., Lan X.: Study on the activation of styrene-based shape memory polymer by medium-infrared laser light. Applied Physics Letters, 96, 111905/1-111905/3 (2010).

DOI: $10.1063 / 1.3353970$

[31] Maitland D. J., Wilson T., Schumann D. L., Baer G.: Laser-activated shape memory polymer microactuators for treating stroke. in 'Lasers and Electro-Optics Society, 2002. LEOS 2002. The $15^{\text {th }}$ Annual Meeting of the IEEE, Glasgow, UK' Vol 1, 359-360 (2002). DOI: $10.1109 /$ LEOS.2002.1134078

[32] Hazelton C. S., Arzberger S. C., Lake M. S., Munshi N. A.: RF actuation of a thermoset shape memory polymer with embedded magnetoelectroelastic particles. Journal of Advanced Materials, 39, 35-39 (2007).

[33] Buckley P. R., McKinley G. H., Wilson T. S., Small W., Benett W. J., Bearinger J. P., McElfresh M. W., Maitland D. J: Inductively heated shape memory polymer for the magnetic actuation of medical devices. IEEE Transactions on Biomedical Engineering, 53, 2075-2083 (2006).

DOI: 10.1109/TBME.2006.877113

[34] Vialle G., Di Prima M., Hocking E., Gall K., Garmestani H., Sanderson T., Arzberger S. C.: Remote activation of nanomagnetite reinforced shape memory polymer foam. Smart Materials and Structures, 18, 115014/1115014/10 (2009).

DOI: $10.1088 / 0964-1726 / 18 / 11 / 115014$

[35] Yu X., Zhou S., Zheng X., Guo T., Xiao Y., Song B.: A biodegradable shape-memory nanocomposite with excellent magnetism sensitivity. Nanotechnology, 20, 235702/1-235702/9 (2009).

DOI: 10.1088/0957-4484/20/23/235702

[36] Zheng X., Zhou S., Xiao Y., Yu X., Li X., Wu P.: Shape memory effect of poly(D,L-lactide) $/ \mathrm{Fe}_{3} \mathrm{O}_{4}$ nanocomposites by inductive heating of magnetite particles. Colloids and Surfaces B: Biointerfaces, 71, 67-72 (2009).

DOI: 10.1016/j.colsurfb.2009.01.009

[37] Razzaq M. Y., Anhalt M., Frormann L., Weidenfeller B.: Thermal, electrical and magnetic studies of magnetite filled polyurethane shape memory polymers. Materials Science and Engineering: A, 444, 227-235 (2007). DOI: $\underline{10.1016 / \text { j.msea.2006.08.083 }}$ 
[38] Lao L. L., Ramanujan R. V.: Magnetic and hydrogel composite materials for hyperthermia applications. Journal of Materials Science: Materials in Medicine, 15, 1061-1064 (2004).

DOI: 10.1023/B:JMSM.0000046386.78633.e5

[39] Pacull J., Gonçalves S., Delgado Á. V., Durán J. D. G., Jiménez M. L.: Effect of polar interactions on the magnetorheology of silica-coated magnetite suspensions in oil media. Journal of Colloid and Interface Science, 337, 254-259 (2009).

DOI: $10.1016 /$ j.jcis.2009.04.083

[40] Weigel T., Mohr R., Lendlein A.: Investigation of parameters to achieve temperatures required to initiate the shape-memory effect of magnetic nanocomposites by inductive heating. Smart Materials and Structures, 18, 025011/1-025011/23 (2009). DOI: $10.1088 / 0964-1726 / 18 / 2 / 025011$

[41] Narendra Kumar U., Kratz K., Behl M., Lendlein A.: Triple-shape capability of thermo-sensitive nanocomposites from multiphase polymer networks and magnetic nanoparticles. Materials Research Society Proceedings, 1190, 55-61 (2009). DOI: $10.1557 /$ PROC-1190-NN03-21
[42] Behl M., Bellin I., Kelch S., Wagermaier W., Lendlein A.: One-step process for creating triple-shape capability of AB polymer networks. Advanced Functional Materials, 19, 102-108 (2009).

DOI: $10.1002 / \mathrm{adfm} .200800850$

[43] Wagermaier W., Zander T., Hofmann D., Kratz K., Narendra Kumar U., Lendlein A.: In situ X-ray scattering studies of poly( $\varepsilon$-caprolactone) networks with grafted poly(ethylene glycol) chains to investigate structural changes during dual- and triple-shape effect. Macromolecular Rapid Communications, 31, 15461553 (2010).

DOI: $10.1002 /$ marc.201000122

[44] Bellin I., Kelch S., Lendlein A.: Dual-shape properties of triple-shape polymer networks with crystallizable network segments and grafted side chains. Journal of Materials Chemistry, 17, 2885-2891 (2007).

DOI: $10.1039 / \mathrm{b} 702524 \mathrm{f}$ 